\title{
Heading Towards $100 \%$ of Renewable Energy Sources Fraction: a critical overview on Smart Energy Systems planning and flexibility measures
}

\author{
Lorenzo Mario Pastore $^{1}$, Gianluigi Lo Basso ${ }^{1}$, Matteo Sforzini ${ }^{1,}{ }^{*}$, and Livio de Santoli ${ }^{1}$ \\ ${ }^{1}$ Department of Astronautics, Electrical and Energy Engineering (DIAEE), Sapienza University of \\ Rome, Via Eudossiana 18, 00184, Rome, Italy
}

\begin{abstract}
The growing penetration of non-programmable energy sources will largely contribute to intensify the renewable capacity firming issues. Providing a higher systems flexibility, i.e. the ability to match the supply and the demand sides as much as possible, is the main challenge to cope with, by adopting new energy planning paradigms. In this framework, different combined strategies, aiming at efficiently integrating that large amount of variable RES (VRES), have to be implemented. In the recent years, the Smart Energy Systems (SES) concept has been introduced to overcome the single-sector approach, promoting a holistic and integrated vision. By that approach, it is possible to exploit synergies between different energy sectors so as to identify the best technical options to globally reduce the primary fossil energy consumption. Starting from a quantitative and qualitative analysis of the most recent international studies dealing with the SES approach, the aim of this paper is to critically review and analyse the role of the main potential flexibility measures applied in the energy planning sector. In detail, Power-to-X and Demand Side Management (DSM) application have been considered, highlighting strengths and weaknesses of such strategies to accomplish the ambitious target of $100 \%$ renewable. From this literature review, it emerges how a single strategy adoption is not enough to guarantee the required flexibility level for the whole energy system. Indeed, the best configuration can be attained by integrating different options matching all the external constraints.
\end{abstract}

\section{Introduction}

In the coming years, energy systems are going to change their structure due to international emission reduction targets and to technological development. Future energy systems will have a high penetration of renewable energy sources and the Variable RES (VRES) share

\footnotetext{
* Corresponding author: matteo.sforzini@uniromal.it
} 
will widely grow. To maximize the energy use hailing from VRES, it will be necessary to modify the energy systems by increasing the system flexibility, i.e. the ability to match energy supply and demand. In fossil fuels-based energy systems, flexibility is ensured by flexible generation capacity. Indeed, fossil sources are very energy dense fuels, which allows them to be easily and cheaply stored, as well as to be used according to demand side requirements. Therefore, a high number of power plants characterised by different response time, allows to accomplish the desired flexibility degree.

When most of the energy generation will be provided by VRES, energy systems will have to develop new strategies to figure out that issue. Indeed, according to Ref.[1], there is a breakdown value for RES integration within current energy systems when large-scale storage devices are not installed; it has been estimated that the allowed RES share is equal to $25 \%$. Flexibility in VRES-based energy systems cannot be provided solely by electric storage since it is an extremely expensive solution. Ref. [2] shows how, in some cases, thermal storage is 100 times cheaper compared to electricity storage. Flexibility must be created by synergies between sectors, planning different conversion phases between subsectors, in order to fully exploit advantages of different energy carriers. Additionally, by optimising cross-sectorial transmission and storage, it is possible to effectively adapt the demand to VRES generation [3].

This vision is identified in the Smart Energy Systems (SES) concept, which was proposed for the first time in 2012 by Lund et al. [1]. That concept was introduced precisely to shift away from single-sector approach into a holistic and integrated approach that allows identifying the best strategies for planning and improving future energy systems [4]. Figures 1 and 2 depict clearly what are the available technologies and potential layouts for merging the different energy sectors at different scales.

a)

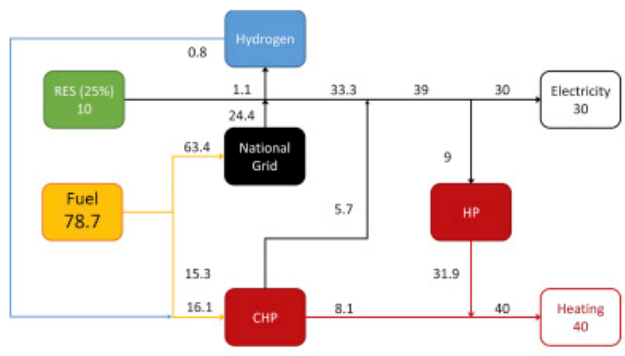

c)

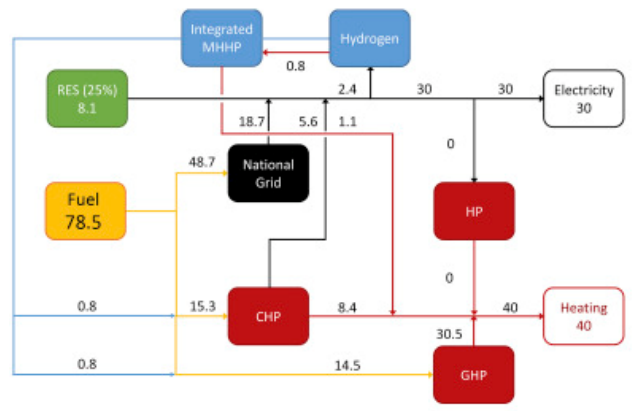

b)

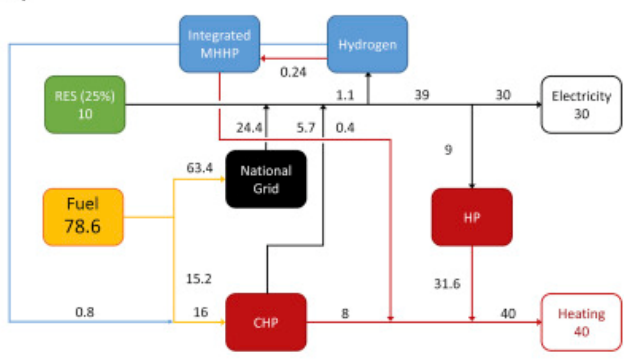

d)

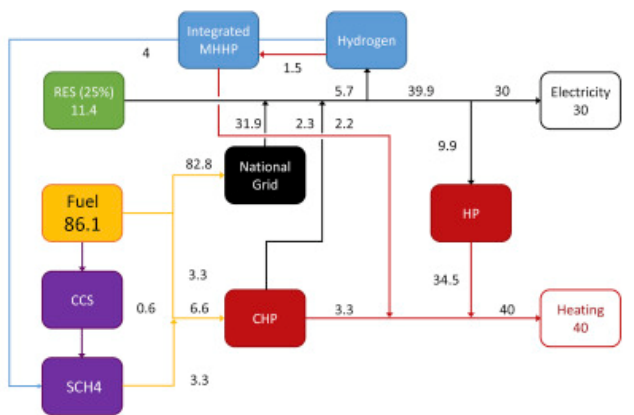

Fig. 1. Energy-flow-diagrams of the optimized energy system with 25\% RES share with Grid Priority for $\mathrm{H}_{2} \mathrm{NG}$ - Hydro-methane mixture (a), MHHP - Metal Hydride Heat Pump (b), GHP - Gas-driven Heat Pump (c) $\mathrm{SCH}_{4}-$ Synthetic Methane (d) technology integration. Source: Elsevier [5] 


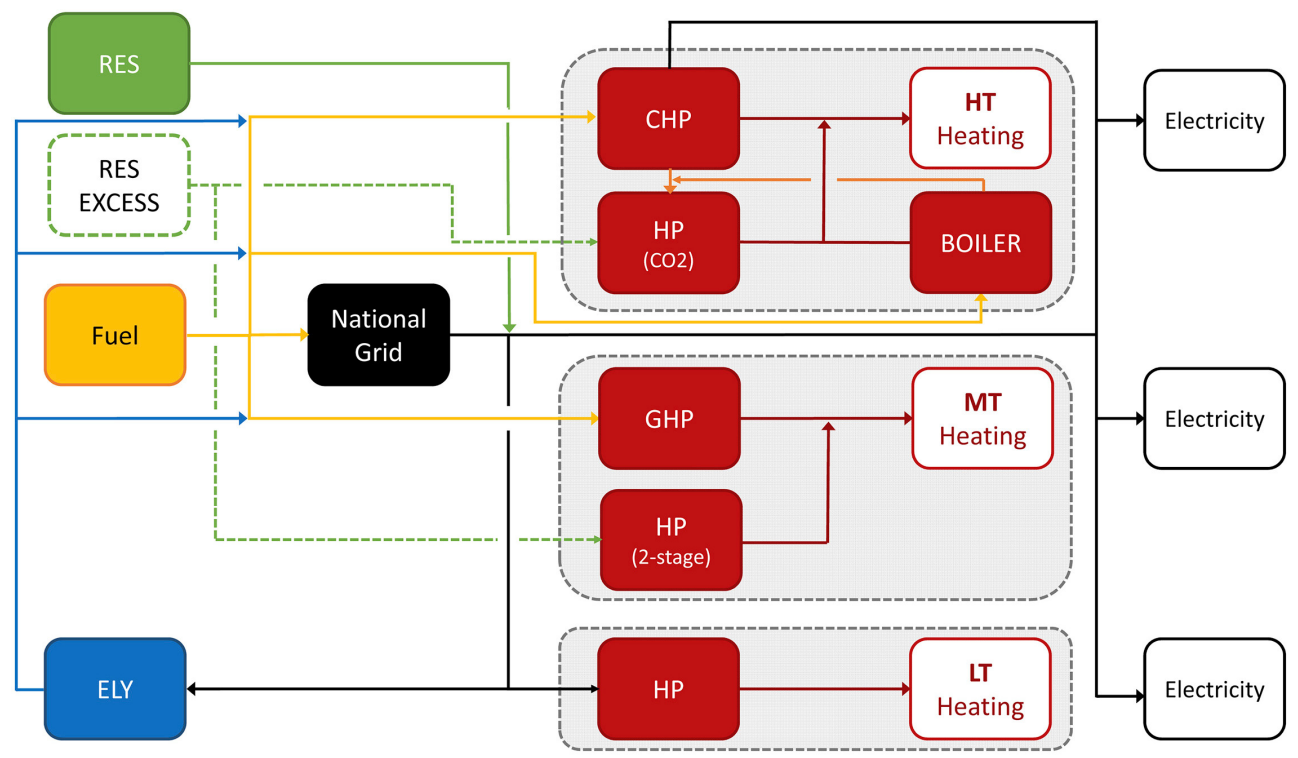

Fig. 2. Aggregated model of the Urban Energy System considering established and electricity-based heating technologies for meeting the diverse heating temperatures by the combination of Power-toGas \& Power-to-Heat integration. Source: Elsevier [6]

Specifically, Figure 1 shows the energy balance of different scenarios based on dimensionless units of energy. Indeed, in that work [5], the authors addressed how the cross sectorial interconnections can lessen the primary fossil energy consumption, starting from an electricity and heating demand equal to 30 units and 40 units, respectively. Referring to a national scenario, it was assumed a total energy need equal to 100 units, where the electricity and heating demands basically represented $30 \%$ and $40 \%$ of overall need. The remaining fraction (i.e. 30\%) referred to the transport sector, which was neglected in that analysis.

The SES approach has been widely used in recent years to investigate energy systems at different scales, from the continental one to individual buildings. A specific application of this approach concerns the energy planning of $100 \%$ renewable energy (RE) systems, i.e. systems characterized by a large share of VRES and where it is not possible to rely on fossil sources flexibility.

Some studies investigated the state of the art in planning $100 \%$ RE scenarios, but they did not address the structure and energy conversions. [7] Several reviews, e.g. Ref [8,9], already studied the flexibility of high RES share systems, but they were mainly focused on the electrical sector.

The present work analyses the entire energy system, by adopting the SES approach. Comparing each other different scenarios of $100 \%$ RE systems, the applied strategies to improve system flexibility have been gone through. The purpose is to critically review and analyse the main flexibility measures applied for planning $100 \% \mathrm{RE}$ scenarios, focusing on cross-sectoral interconnections so as to analyse their potential role in future energy systems.

\subsection{Outline}

Chapter 2 summarises the main studies that use the SES approach and previous reviews on the topic. In chapter 3 the method of choosing and analysing scenarios has been explained and the selected scenarios are presented. In chapter 4 the scenarios have been analysed and 
compared to identify the most frequently used flexibility measures along with their potential role in $100 \%$ RE systems. Finally, chapter 5 summarises the main findings of this study.

\section{Literature Review}

In recent years the SES approach has been used for energy planning at different levels. Connolly et al. [10] developed a scenario for a $100 \%$ renewable energy system in Europe by 2050 , demonstrating its technical and socio-economic feasibility.

Dominković et al. [11] presented the transition phases to be followed until 2050 in order to achieve zero carbon energy society for South East Europe.

In regards of energy analysis at national level, one of the most investigated countries is Denmark. In 2009 Lund and Mathiesen [12] planned a strategy to make the Danish energy system at 50\% RES in 2030 and 100\% RES in 2050.

Thereafter, the same authors et al. [13] presented "The IDA's Energy Vision 2050: a Smart Energy System strategy for $100 \%$ renewable Denmark in 2050", consisting of a detailed description on how to get a complete decarbonisation of Danish energy system.

Further examples of smart energy systems approach application at national level are the research projects presented by Vidal-Amaro et al. in Mexico [14] and Connolly et al. in Ireland [15].

Thus, the smart energy systems approach has been widely applied to urban scale, e.g. Aalborg [16], Copenhagen [17] and Zagreb [18].

Other studies investigated the approach suitability in small communities. For instance, Groppi et al. [19] studied the conversion into a cleaner and low-carbon energy system for small Mediterranean Island within the INTERREG-EUROPE funding program.

The application of smart energy systems is feasible even to the smallest energy systems, such as the individual buildings. Lo Basso et al. [20] investigated on the potential advantages hailing from the cross-sectoral approach for a historic building in the centre of Rome.

In 2017 Lund et al. [4] made a first review on Smart Energy Systems, proposing a unique definition and presenting a scientific literature survey within that research field. In ref. [21], Deason compared $100 \%$ renewable energy system scenarios focusing on flexibility and cost.

Recently, Hansen et al. [22] analysed the state and prospects of research in the $100 \%$ RE systems planning. The study analysed and compared 180 articles published since 2004 .

\section{Methods}

The first step is the selection of relevant studies which are suitable for the analysis. Several criteria have been taken into account for shortlisting those research activities:

- $\quad$ the development of a 100\% RE scenarios;

- $\quad$ an analysis dealing with the whole energy system using the SES approach;

- $\quad$ the use of a high-temporal resolution and short-term model for the energy system simulations;

- $\quad$ an analysis carried out at national level or pertaining groups of nations;

- the application within the European Union.

It is worth of noticing how the choice of computer tools is a fundamental issue, as the integration of VRES requires a high temporal resolution model to perform a precise analysis of system flexibility. 
The main computer tools for energy systems simulation can be categorised into short-term and long-term models. Short-term models allow to optimize the system structure in a reference year. Long-term models focus on optimizing the transition by evaluating the complete pathway of energy system up to the reference year [23]. Only short-term models have been considered here, since this study focuses on the system structure analysis and not on the transition to $100 \%$ RE systems.

Moreover, the models must be able to simulate all energy system sectors and the foreseeable interconnections between them.

As aforementioned, studies at national level or concerning groups of nations have been considered as a driver for selection. All of scenarios regarding small towns or cities have been neglected in order to limit the case studies to be analysed.

Additionally, in the groups of nations analysis, the cross-border interconnection is an important and not negligible factor, which differentiates them from a national discussion. Furthermore, only scenarios concerning regions within the European Union have been considered, so as to limit the differences in geographical and socio-economic conditions.

Finally, the essential criterion is the SES approach application, since it is the most important topic for this investigation, which aims at identifying the role of interconnection between energy sectors.

Once the suitable scenarios are identified, the final energy system configuration and the strategies adopted to get the system flexibility have been compared each other.

Seven studies meeting the selected criteria have been identified, and scenarios details have been summarised in Table 1 .

Table 1. Selected scenarios details.

\begin{tabular}{|c|c|c|c|c|}
\hline Region & Authors & Year & $\begin{array}{c}\text { Computer } \\
\text { tool }\end{array}$ & Ref. \\
\hline Macedonia & Ćosić et al. & 2012 & EnergyPLAN & {$[24]$} \\
\hline Ireland & Conolly et al. & 2014 & EnergyPLAN & {$[15]$} \\
\hline Europe & Connolly et al. & 2015 & EnergyPLAN & {$[10]$} \\
\hline Denmark & Mathiesen et al. & 2015 & EnergyPLAN & {$[13]$} \\
\hline $\begin{array}{c}\text { South-East } \\
\text { Europe }\end{array}$ & Dominković et al. & 2016 & EnergyPLAN & {$[11]$} \\
\hline Finland & Child et al. & 2016 & EnergyPLAN & {$[25]$} \\
\hline Germany & Hansen et al. & 2019 & EnergyPLAN & {$[26]$} \\
\hline
\end{tabular}

Five of these scenarios concern European Member states, one concerns a group of southern European states and one refers the whole European Union. All the selected models use EnergyPLAN as a computer tool for simulating the energy system.

EnergyPLAN is a deterministic input-output model developed by Lund et al. at Aalborg University [27]. The model includes all energy sectors and is able to interconnect different sub-sectors by a wide range of technologies (see Figure 3).

It operates at hourly resolution by balancing, for each step, the supply and demand of electricity, heating, cooling and fuel or electricity for transportation. It includes several storage options and cutting-edge technologies [28]. 


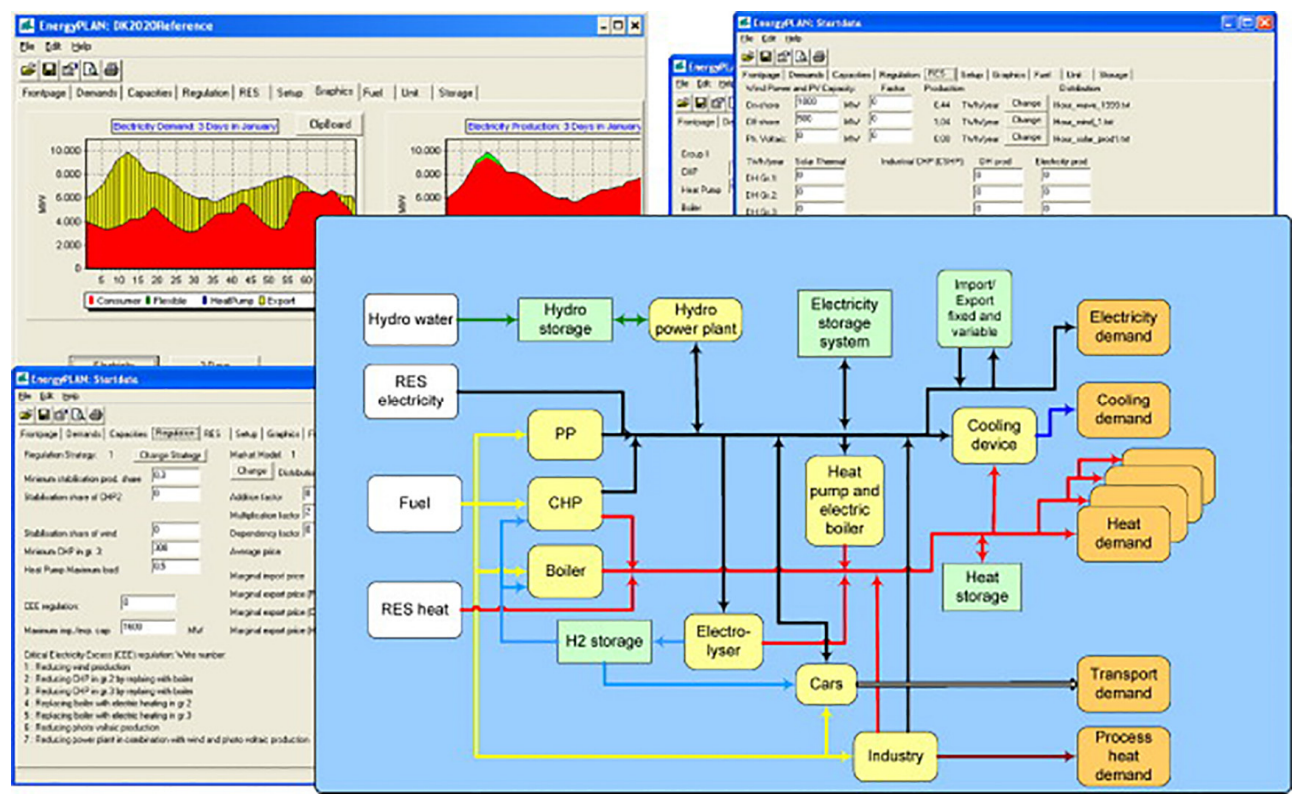

Fig. 3. Flow diagram of energy technologies in the EnergyPLAN computer model. Source: Elsevier [12]

\section{Results and discussion}

In this section, the selected studies have been briefly described, highlighting their main characteristics. Thereafter, the most important flexibility measures and the VRES share are compared and analysed. Finally, the discussion of cross-sectoral interconnections and the demand side management (DSM) has been expanded including further studies, to pointing out the strengths and weaknesses of such strategies.

In 2012 Ćosić et al. studied a potential structure for a 100\% RE system in Macedonia [24]. The target year is 2050 whilst the developed intermediate scenario is by 2030 . The Macedonian energy system can rely heavily on hydroelectric generation. That is a decisive factor in choosing a large increase in PHS (Pumped Hydro Storage) capacity to cope with the renewables' discontinuity. In addition, the large presence of hydroelectric allows to reduce biomass use in electricity generation. The study does not consider the Power-to-gas (PtG) option, relying exclusively on the interconnection between the electric and heating sector, by adopting individual and large-scale heat pumps.

In 2014, Connolly and Mathiesen developed a seven-step plan defining one potential pathway to get to $100 \%$ RE system in Ireland [29]. The seven stages are listed as follows:
1) reference,
2) introduction of district heating,
3) installation of small and large-scale heat pumps,
4) reducing grid regulation requirements,
5) adding flexible electricity demands and electric vehicles,
6) producing synthetic methanol / DME for transport,
7) using synthetic gas to replace the remaining fossil fuels. 
This step-by-step approach was also used in 2015, by the same authors together with H. Lund, for developing the Smart Energy Europe plan[10]. In this study, 9 steps were developed for the transition to a $100 \%$ RE system. Different scenarios for heating purposes have been considered, and the best choice has proved to be the HPs use for both individual and heat network. Identifying the maximum potential of biomass use represents a fundamental constraint in planning. Moreover, in that study, the final steps for the $100 \%$ RE system achievement are the so-called electro-fuels production and their use in the various energy sectors.

In 2015, Mathiesen et al. developed a detailed plan for 100\% RE system in Denmark based on the SES approach [13]. Each energy sector, intended as electricity, heating and cooling, industries and transport, was analysed exploiting the synergies between themselves for identifying the best options to apply.

Dominković et al. proposed a Zero carbon energy system for South East Europe in 2050 [11]. The wide deployment of hydroelectric justifies a broad use of PHS and allows to limit the biomass exploitation.

The use of electro-fuels is relegated exclusively to the heavy transport sector. Two scenarios have been developed by 2050: a main one, and another one which has been built under the hypothesis of halving hydroelectric production, i.e. " $50 \%$ less hydro". For the subsequent comparison, the main scenario is considered, but it is worth of highlighting that in " $50 \%$ less hydro scenario" the biomass consumption has more than doubled. Indeed, the system flexibility without the massive PtG integration, it is not enough to allow a greater VRES use.

In 2016, Child and Breyer studied a 100\% RE scenario for Finnish energy system [25]. The geographical position strongly affects the energy demand as far as the VRES production, especially the PV plants, causing a wide variability season by season. Therefore, the PtG option was chosen to allow long-term energy storage.

Unlike other studies, the PtG is the main strategy to guarantee system flexibility in both short and long term. Several scenarios have been developed, the selected one for the analysis involves the nuclear power complete decommissioning and a sustainable biomass use. In that scenario, more than $45 \%$ of the annual electricity hailing from VRES is converted by PtG subsystems.

Recently, Hansen et al. studied an energy system transition towards $100 \%$ RE in Germany, by 2050 [26]. That plan analysed the different energy sectors and the foreseeable synergies between them.

In regards of heavy transport, 4 different scenarios were analysed, such as hydrogen by fuel cell, electricity, $\mathrm{CO}_{2}$ electro-fuel, bio-electro-fuel. Furthermore, each scenario was simulated with and without the maximum constraint equal to $5 \%$ of electricity production excess, i.e. the annual produced electricity which is not consumed.

An important criterion to make the right choice is the biomass consumption threshold. Indeed, only the hydrogen use by fuel cell, removing that constraint on electricity excess, is compatible with the estimated biomass potential. That scenario is the only one considered for the subsequent analysis.

Table 2 summarizes the main proposed actions in each study and Figure 1 shows the VRES share in electricity generation.

The VRES share is very similar for all scenarios, exception for Macedonia and S-E Europe. Indeed, these regions are characterized by a relevant number of hydroelectric power plants, which provide a higher share of programmable generation. That issue affects the strategies choice to be adopted, therefore the proposed programs for those regions foresee a large increase in PHS capacity.

It emerges also correlations between the high hydroelectric share and the low or almost null PtG share and the lower VRES share versus the wide use of PHS. All the other scenarios 
were characterised by VRES share in electricity production close to $80 \%$, and that feature is likely due to a similar limit of biomass exploitation in those territories.

Table 2. Flexibility measures for each analysed scenario.

\begin{tabular}{|c|c|c|c|c|c|c|c|c|c|c|c|c|}
\hline 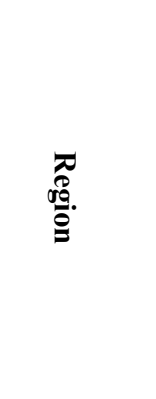 & 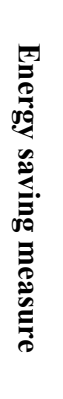 & 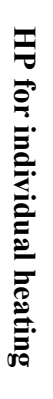 & 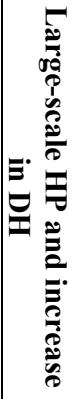 & 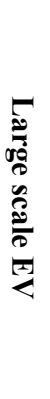 & 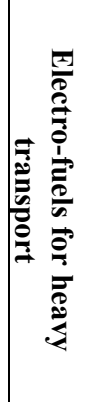 & 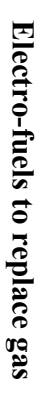 & 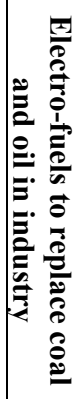 & 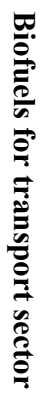 & 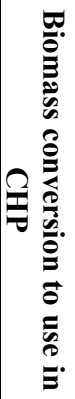 & 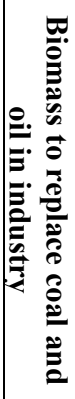 & 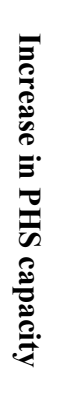 & 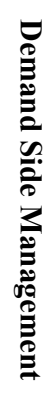 \\
\hline Macedonia & $\mathrm{X}$ & $\mathrm{X}$ & $\mathrm{X}$ & $\mathrm{X}$ & & & & $\mathrm{X}$ & $\mathrm{X}$ & $\mathrm{X}$ & $\mathrm{X}$ & \\
\hline Ireland & & $\mathrm{X}$ & $\mathrm{X}$ & $\mathrm{X}$ & $\mathrm{X}$ & $\mathrm{X}$ & $X$ & $\mathrm{X}$ & $\mathrm{X}$ & $X$ & & $\mathrm{X}$ \\
\hline Europe & $\mathrm{X}$ & $\mathrm{X}$ & $\mathrm{X}$ & $\mathrm{X}$ & $\mathrm{X}$ & $\mathrm{X}$ & $\mathrm{X}$ & $\mathrm{X}$ & $\mathrm{X}$ & $\mathrm{X}$ & & $\mathrm{X}$ \\
\hline Denmark & $\mathrm{X}$ & $\mathrm{X}$ & $\mathrm{X}$ & $\mathrm{X}$ & $\mathrm{X}$ & $\mathrm{X}$ & & $\mathrm{X}$ & $\mathrm{X}$ & $X$ & & $\mathrm{X}$ \\
\hline $\begin{array}{l}\text { South-East } \\
\text { Europe }\end{array}$ & X & X & X & X & $X$ & & & $X$ & X & X & $X$ & \\
\hline Finland & $\mathrm{X}$ & $\mathrm{X}$ & $\mathrm{X}$ & $\mathrm{X}$ & $\mathrm{X}$ & $\mathrm{X}$ & & $\mathrm{X}$ & $\mathrm{X}$ & $\mathrm{X}$ & & $\mathrm{X}$ \\
\hline Germany & $\mathrm{X}$ & $\mathrm{X}$ & $X$ & X & $\mathrm{X}$ & & & & $\mathrm{X}$ & $X$ & & \\
\hline
\end{tabular}

\section{Variable and programmable generated electricity}

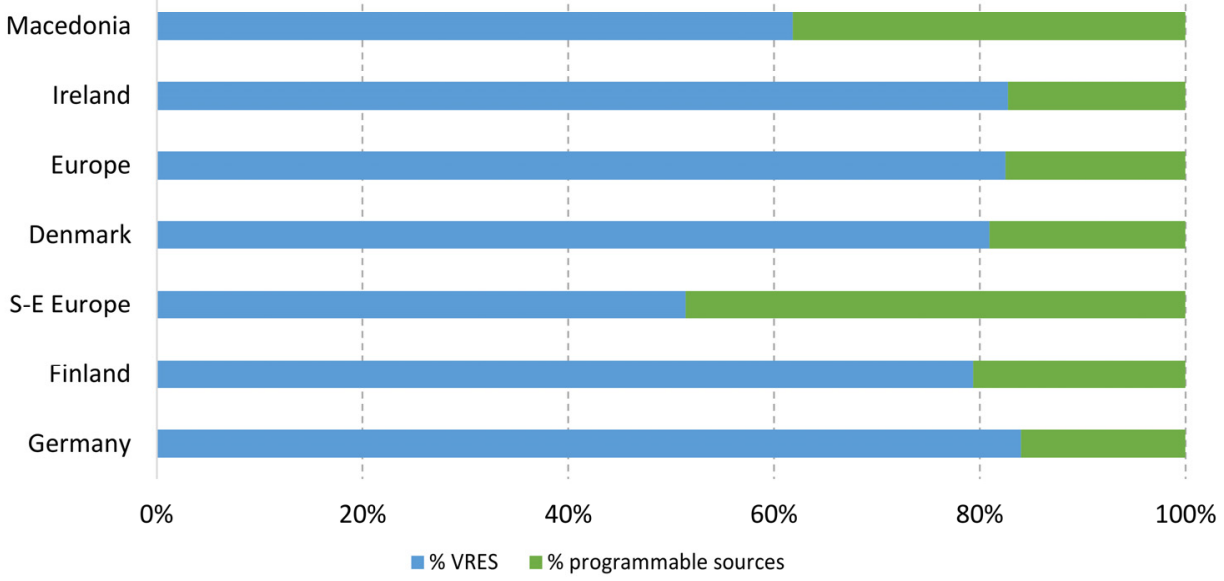

Fig. 4. Variable and programmable share of electricity generated 
A common factor in the different studies is the maximum biomass potential identification, which often drives the best scenario determination. Biomass is widely exploited in those sectors where the electrification degree is poor owing to infrastructural constraints. For that reason, it is often used together with electro-fuels synthesis. In addition, the biomass use in CHPs is always foreseen, as it allows to balance the electricity needs as well. Energy saving measures were accounted for in all scenarios, exception for the Ireland case study, which does not include them in the analysis, but it recognizes them as crucial in the energy systems decarbonisation. Those measures can be considered as indirect strategy to increase the system flexibility. Yet, they are included in the analysis since they have a strong impact on the energy balance in each step, therefore on the best option search. As regards the cross-sectoral interconnections and the demand side management (DSM), discussion was expanded including further studies, to analyse other viable strategies within the smart energy systems framework.

\subsection{Power-to-Heat and District Heating}

The Power-to-Heat (PtH) assumes a fundamental role in all of considered scenarios. Since the increase in RES share implies a growth in the electric carrier penetration, one of the most promising solutions is to meet heating and cooling demands by means of heat pumps (HPs). That technical solution allows the use of thermal storages instead of BES (Battery Energy Storage), so as to accumulate the electricity surplus. It is noteworthy that under specific hypotheses and operating thermal storages can be 100 times cheaper than the electric ones. In the analysed studies, the common strategy is to provide heat to DH (District Heating) systems in all those areas characterised by high population density, while in the unreachable buildings clusters individual HPs have been considered. Decentralized $\mathrm{PtH}$ solutions allow to convert electricity nearby heat demand locations, however not all solutions include thermal energy storage.

Research effort in recent years was focused on the development of 4th Generation District Heating (4GDH), i.e. a smart thermal grid providing low grade heat (e.g. water temperature equal to $50-70^{\circ} \mathrm{C}$ ) with low distribution network losses [30]. The low network temperature also leads to an excellent integration into smart energy systems contributing to reduce the electricity sector inefficiencies [31]. According to Ref. [32], old building stocks, i.e. the existing ones together with their own thermal networks, can be refurbished and converted into a new generation dwellings a cost-effective way. Indeed, the benefits, mainly due to the higher system efficiency and interconnection between sectors, far outweigh the costs. Furthermore, DHs already guarantees benefits integrating the current systems, since they are able to recover waste heat from industrial processes and from thermal power plants [33]. However, not all dwellings can be served by $\mathrm{DH}$; that option is not convenient in areas with low population density or far from the production sites [34]. Furthermore, in some cities, especially in the historical centres, new thermal grids construction, are more complex and more expensive. Anyway, the DH coverage potential is very wide. According to ref. [35], DHs can theoretically satisfy about $50 \%$ of heating demand in Europe.

It is important to highlight how the PtH solution, by HPs exploitation, requires several precautions and adjustments, resulting in higher costs. As a matter of fact, the low supply water temperature of HPs and 4GDH needs larger size of end-user terminals. Furthermore, there are greater electricity flows over the wires linking production sites with conversion nodes represented by the HPs. That requires important modernizations and the electricity networks repowering [5]. 
In regards of energy planning, it is important to identify a trade-off between heat saving and supplying heat. In ref. [36] two methodologies were proposed to identify when the cost of heat savings become more expensive than the cost associated to sustainable heat supply.

In conclusion, $\mathrm{PtH}$ is an essential solution for planning $100 \% \mathrm{RE}$ systems. Notwithstanding, as shown in the articles analysed, specifically in [6,7], the full use of PtH is not enough to reach the aforementioned high VRES share (about 80\%). Integration with other strategies is therefore necessary.

\subsection{Power-to-Gas}

Another option to use the electricity excess deriving from VRES is to produce hydrogen by electrolytic processes. The renewable Hydrogen can be used directly or converted into other electro-fuels by the catalytic synthesis together with either Carbon Monoxide (CO) or Carbon Dioxide $\left(\mathrm{CO}_{2}\right)$ [37].

In the analysed studies, the most relevant electro-fuels are methanol, DME and methane. In Ref. [26] the direct use of hydrogen in fuel cells for heavy vehicles was also evaluated. In all selected studies, exception for what was reported in in Ref. [24], electro-fuels were used to meet the demand for heavy transport; 4 out of 7 scenarios involved the methane synthesis and its use. Only Ref. [6,7] used electro-fuels together with bio-fuels in industry demand. Ref. [25] based its system flexibility on the PtG, owing to the need of long-term storages to meet seasonal variations in supply and demand sides.

The hydrogen use versatility, due to the its subsequent syntheses, allows its exploitation in different energy sectors increasing system flexibility and integrating larger capacity of VRES. For instance, in Ref [10], the full use of electro-fuels allows the energy system shifting from just over $40 \%$ RES to $100 \%$ RES.

A solution which was not used in those scenarios, consists of blending hydrogen with NG so as to feed the existing pipelines That feature was addressed in Ref [38]. The strength points of $\mathrm{H}_{2} \mathrm{NG}$ (Hydrogen Enriched Natural Gas blends) implementation consist of eliminating further chemical-physical transformations, which complicate processes and increase costs; eliminating dedicated and expensive infrastructures for pure hydrogen storage, which implies restrictive measures to mitigate explosion risks and other safety issues [39].

The maximum share of Hydrogen injection into Natural Gas Grid was been the subject of several studies. According to Ref. [40]. Hydrogen fractions in the mixtures up to $3 \%$ vol. does not require any modification to both supply and user sides. That solution is suitable especially for all those countries characterised by wide and capillary Natural Gas networks, since large investments are not required for constructing new infrastructures, but the existing ones could be easily upgraded [5]. Additionally, where DH is strongly hindered by the territories morphology as well as the urban topology, the $\mathrm{H}_{2} \mathrm{NG}$ application contributes positively for greening both natural (NG) and heating sectors.

Furthermore, the potential of that solution is greater when the whole transition phase, starting from the current state and heading towards the $100 \% \mathrm{RE}$ system, is analysed. As a matter of fact, NG will still play an important role in the most of energy transition scenarios, representing, in the first period, an efficient and economic means for storing hydrogen.

In NG-based countries, where heating demand in buildings is usually supplied at high and medium temperature, $\mathrm{H}_{2} \mathrm{NG}$ allows to integrate electric VRES, and to meet heating demand limiting costs for infrastructures modernization [41]. Finally, in Ref. [6] it was emphasized that $\mathrm{PtG}$ is not an alternative solution to $\mathrm{PtH}$; rather, it is feasible and more convenient to combine them each other to effectively satisfy medium and high temperature users, improving cross-sectors interconnection as well. Moreover, further mutual connections can 
be obtained by $\mathrm{DH}$. Since the $\mathrm{CO}_{2}$ methanation reaction is an exothermic process, part of that waste heat can be recovered for supplying the heating networks [25].

\subsection{Electric Vehicles and Vehicle-to-Grid}

The large-scale integration of electric vehicles (EVs) is a measure used in all the analysed scenarios. EVs are mainly used for replacing internal combustion engines in light transport. In most scenarios, the transport demand fraction covered by electric vehicles is approximately $80 \%$. In ref. [25] there was a large-scale use of bio-fuels and electro-fuels, where electric vehicles covered only $28.6 \%$ of the overall transport demand. That choice was due to the wide PtG use to balance the VRES generation. The partial or complete light transport electrification process provides a large amount of electricity storage. The storage capacity of a single battery is low, but when the entire vehicles fleet is considered, the overall capacity it is extremely high. Considering the European scenario, the overall storage capacity is huge. Typical storage capacity of today's EV is $25 \mathrm{kWh}$, and currently, there are around 250 million vehicles in Europe. If $80 \%$ of fossil fuel vehicles were replaced in electric ones, there will be an aggregated electricity storage of 5 TWh [10]. However, dedicated infrastructures are needed to adapt the demand side to intermittent RES production [42]. By the EVs introduction, the uncertainty level also increases on the demand side. The further step is represented by Vehicle-to-grid (VtG) technology, by which EVs can basically become providers to stabilize the production side as well. Indeed, EVs could not only responsible of electricity up-takes, but they also serve as storage devices for power grids. When vehicles are parked, they feed energy back into the grid if required [43]. However, higher participation rates in $\mathrm{VtG}$ connections may require financial incentive mechanisms, which are not commonly considered in planning studies. Up to date, electric vehicles are in fact an emerging technology from a commercial point of view, since levels of air pollution in the big cities are growing more frequently. Nevertheless, a sudden decrease in specific costs along with an increase in the batteries capacity and charging infrastructure will be necessary in the next years [44]. Furthermore, EVs are playing an important role in the energy resources planning, indeed they allow avoiding the biomass consumption for light transport and to conserve it for other purposes.

\subsection{Demand Side Management}

Demand side management (DSM) measures have been addressed in 4 out of 7 selected scenarios. In those ones, the general approach consists of identifying a load capacity that can be efficiently shifted and programmed on the basis of VRES outputs. By those techniques, the RES excess can be generally reduced since the load profiles shape is modified to be flattened as much as possible. In such studies, the main target was the recognition of technical optimum instead of an economic one. However, when real applications are accounted for, the electricity spot market outcomes are no more negligible, seeing that the power up-takes timeseries influence daily prices. Having said this, the overall measure cost could be higher than the estimated one for the reference scenarios. Different DSM applications were traditionally used for peak power shaving and only in recent years they have been exploited to balance the VRES generation [45]. Nowadays, the most effective applications deal with the management of industrial demand. Nonetheless, to balance VRES outputs, the implementation of such strategies to the residential sector seems to be promising. The DSM activities are suitable either for single dwelling or for buildings clusters. By constituting virtual third parties, also known as aggregators, those subjects are able to gather huge amounts of energy for trading them on advantageous terms. In regards of aggregators, it is crucial for them, firstly to accurately estimate the dwellings clusters 
profile, secondly to keep under control shiftable loads [46]. In a new context moving towards the distributed generation, where residential photovoltaic plants are widespreading, flexible demands allow to lessen the energy amount taking advantages of net metering mechanism. In such a way, the DSM contributes to mitigate the grid interferences caused by residential prosumers. An effective intervention to manage the electricity demand in buildings is to switch from fossil fuels to electric-driven heating systems [47]. That solution turned out to be interesting especially in Italy, where the residential heating systems are poorly electrified [48]. Anyway, some barriers have been detected for the DSM measures dissemination. Those hurdles mainly concern: the lack of a reliable and cheap ICT infrastructure; the availability of timely energy and price information [49]; the low electrification degree for heating purposes; finally, the implantation of profitable incentive schemes for technologies financing [50]. However, even though the capital expenditure associated to the installation within households of those equipment are relatively low, the energy savings are moderate and pay-back periods range between 5 and 10 years [51].

\section{Conclusions}

This article goes through the sectorial international literature to identify the main flexibility measures which have been applied for planning high VRES energy systems.

Indeed, several research projects explored different pathways to get the ambitious target of designing 100\% RE scenarios using the Smart Energy System approach. The authors, by shortlisting the most relevant works, reported what are the most promising strategies to decarbonise current energy systems, discussing also, the strength points of each technique and the potential limitations.

The main findings of this analysis can be summarized as follows:

- Power-to-Heat plays generally a key role to reduce the primary fossil energy consumption, as it is based on an efficient and well-proven technology. By that strategy, it is possible to meet the heating and cooling demands deploying heat pumps for both centralised generation and for individual users;

- The development of a 4th Generation District Heating allows the large-scale integration between the electric and heating sectors. The low energy losses and the great interconnection capacity do so that $4 \mathrm{GDH}$ is a suitable measure in each energy scenario. Notwithstanding, only a few clusters of existing buildings can be linked to heating networks in a cost-effective way owing to territories morphology;

- In the most of analysed scenarios, the Power-to-Gas option contributes to achieve a $100 \%$ renewable energy system, favouring the completely fossil fuels replacement. From data analysis it emerges how a correlation between the electro-fuels wide use and greater VRES share values exists;

- Electro-fuels are often used together with biofuels in those sectors where the endusers electrification for heating purposes is not easy to be accomplished.

- In each scenario, a precise assessment of the exploitable biomass potential is crucial. It represents one of the most significant constraints in the $100 \% \mathrm{RE}$ systems planning.

- The use of biomass products for fuelling CHPs is fundamental in all scenarios, seeing that they are programmable generation systems able to instantly balance the VRES.

- Electric vehicles connection is an additional opportunity that has been investigated in all scenarios since it allows to decarbonise the light transport sector. The accurate scheduling of EVs recharges along with the $\mathrm{VtG}$ implementation lead to an important improvement in the system flexibility. 
- Several studies investigated on the DSM programs feasibility especially in the industrial sector and in the residential one. Referring to this latter, appropriate energy and cost savings can be attained only under the hypothesis of a high electrification degree in the energy end-use.

In conclusion, it can be stated that:

A single strategy is not enough to guarantee the required flexibility level for the whole energy system. The best configuration can be accomplished by integrating different options matching all the external constraints.

\section{References}

1. Lund, H.; Andersen, A.N.; Østergaard, P.A.; Mathiesen, B.V.; Connolly, D. From electricity smart grids to smart energy systems - A market operation based approach and understanding. Energy 2012, 42, 96-102, doi:10.1016/j.energy.2012.04.003.

2. Lund, H.; Østergaard, P.A.; Connolly, D.; Ridjan, I.; Mathiesen, B.V.; Hvelplund, F.; Thellufsen, J.Z.; Sorknses, P. Energy storage and smart energy systems. Int. J. Sustain. Energy Plan. Manag. 2016, 11, 3-14, doi:10.5278/ijsepm.2016.11.2.

3. Jacobson, M.Z.; Delucchi, M.A.; Cameron, M.A.; Frew, B.A. Low-cost solution to the grid reliability problem with $100 \%$ penetration of intermittent wind, water, and solar for all purposes. Proc. Natl. Acad. Sci. U. S. A. 2015, 112, 15060-15065, doi:10.1073/pnas.1510028112.

4. Lund, H.; Østergaard, P.A.; Connolly, D.; Mathiesen, B.V. Smart energy and smart energy systems. Energy 2017, 137, 556-565, doi:10.1016/j.energy.2017.05.123.

5. Nastasi, B.; Lo Basso, G. Hydrogen to link heat and electricity in the transition towards future Smart Energy Systems. Energy 2016, 110, 5-22, doi:10.1016/j.energy.2016.03.097.

6. Nastasi, B.; Lo Basso, G.; Astiaso Garcia, D.; Cumo, F.; de Santoli, L. Power-togas leverage effect on power-to-heat application for urban renewable thermal energy systems. Int. J. Hydrogen Energy 2018, 43, 23076-23090, doi:10.1016/j.ijhydene.2018.08.119.

7. Hansen, K.; Breyer, C.; Lund, H. Status and perspectives on 100\% renewable energy systems. Energy 2019, 175, 471-480, doi:10.1016/j.energy.2019.03.092.

8. Deason, W. Comparison of $100 \%$ renewable energy system scenarios with a focus on flexibility and cost. Renew. Sustain. Energy Rev. 2018, 82, 3168-3178, doi:10.1016/j.rser.2017.10.026.

9. Cochran, J.; Mai, T.; Bazilian, M. Meta-analysis of high penetration renewable energy scenarios. Renew. Sustain. Energy Rev. 2014, 29, 246-253. 
10. Connolly, D.; Lund, H.; Mathiesen, B. V. Smart Energy Europe: The technical and economic impact of one potential 100\% renewable energy scenario for the European Union. Renew. Sustain. Energy Rev. 2016, 60, 1634-1653, doi:10.1016/j.rser.2016.02.025.

11. Dominković, D.F.; Bačeković, I.; Ćosić, B.; Krajačić, G.; Pukšec, T.; Duić, N.; Markovska, N. Zero carbon energy system of South East Europe in 2050. Appl. Energy 2016, 184, 1517-1528, doi:10.1016/j.apenergy.2016.03.046.

12. Lund, H.; Mathiesen, B. V. Energy system analysis of $100 \%$ renewable energy systems-The case of Denmark in years 2030 and 2050. Energy 2009, 34, 524-531, doi:10.1016/j.energy.2008.04.003.

13. Vad, B.; Roth, S.; Zinck, J. Aalborg Universitet IDA's Energy Vision 2050 Søgaard; Drysdale, Dave ; Connolly, David ; Østergaard, Poul Alberg; 2015; ISBN 9788791404788.

14. Vidal-Amaro, J.J.; Sheinbaum-Pardo, C. A transition strategy from fossil fuels to renewable energy sources in the mexican electricity system. J. Sustain. Dev. Energy, Water Environ. Syst. 2018, 6, 47-66, doi:10.13044/j.sdewes.d5.0170.

15. Connolly, D.; Mathiesen, B.V. A technical and economic analysis of one potential pathway to a $100 \%$ renewable energy system. Int. J. Sustain. Energy Plan. Manag. 2014, 1, 7-28, doi:10.5278/ijsepm.2014.1.2.

16. Alberg Østergaard, P.; Mathiesen, B.V.; Möller, B.; Lund, H. A renewable energy scenario for Aalborg Municipality based on low-temperature geothermal heat, wind power and biomass. Energy 2010, 35, 4892-4901, doi:10.1016/j.energy.2010.08.041.

17. Mathiesen, Brian Vad; Lund, Rasmus Søgaard; Connolly, David; Ridjan, Iva; Nielsen, S. Copenhagen Energy Vision 2050: A sustainable vision for bringing a capital to $100 \%$ renewable energy. 2015, 100 .

18. Bačeković, I.; Østergaard, P.A. A smart energy system approach vs a nonintegrated renewable energy system approach to designing a future energy system in Zagreb. Energy 2018, 155, 824-837, doi:10.1016/j.energy.2018.05.075.

19. Groppi, D.; Astiaso Garcia, D.; Lo Basso, G.; De Santoli, L. Synergy between smart energy systems simulation tools for greening small Mediterranean islands. Renew. Energy 2019, 135, 515-524, doi:10.1016/j.renene.2018.12.043.

20. Lo Basso, G.; Rosa, F.; Astiaso Garcia, D.; Cumo, F. Hybrid systems adoption for lowering historic buildings PFEC (primary fossil energy consumption) - A comparative energy analysis. Renew. Energy 2018, 117, 414-433, doi:10.1016/j.renene.2017.10.099. 
21. Deason, W. Comparison of $100 \%$ renewable energy system scenarios with a focus on flexibility and cost. Renew. Sustain. Energy Rev. 2018, 82, 3168-3178, doi:10.1016/j.rser.2017.10.026.

22. Hansen, K.; Breyer, C.; Lund, H. Status and perspectives on 100\% renewable energy systems. Energy 2019, 175, 471-480, doi:10.1016/j.energy.2019.03.092.

23. Després, J.; Hadjsaid, N.; Criqui, P.; Noirot, I. Modelling the impacts of variable renewable sources on the power sector: Reconsidering the typology of energy modelling tools. Energy 2015, 80, 486-495, doi:10.1016/j.energy.2014.12.005.

24. Ćosić, B.; Krajačić, G.; Duić, N. A 100\% renewable energy system in the year 2050: The case of Macedonia. Energy 2012, 48, 80-87, doi:10.1016/j.energy.2012.06.078.

25. Child, M.; Breyer, C. Vision and initial feasibility analysis of a recarbonised Finnish energy system for 2050. Renew. Sustain. Energy Rev. 2016, 66, 517-536, doi:10.1016/j.rser.2016.07.001.

26. Hansen, K.; Mathiesen, B.V.; Skov, I.R. Full energy system transition towards $100 \%$ renewable energy in Germany in 2050. Renew. Sustain. Energy Rev. 2019, 102, 1-13, doi:10.1016/j.rser.2018.11.038.

27. Lund, H. EnergyPLAN Advanced Energy Systems Analysis Computer Model. Aalborg Univ. Denmark 2015, 1, 1-114.

28. EnergyPLAN Advanced Energy Systems Analysis Computer Model Documentation Version 14;

29. Planning, S.E.; Vol, M. A technical and economic analysis of one potential pathway to a $100 \%$ renewable energy system. Int. J. Sustain. Energy Plan. Manag. 2014, 01, 7-28.

30. Lund, H.; Werner, S.; Wiltshire, R.; Svendsen, S.; Thorsen, J.E.; Hvelplund, F.; Mathiesen, B.V. 4th Generation District Heating (4GDH). Integrating smart thermal grids into future sustainable energy systems. Energy 2014, 68, 1-11, doi:10.1016/j.energy.2014.02.089.

31. Lund, H.; Duic, N.; Østergaard, P.A.; Mathiesen, B.V. Smart energy systems and 4th generation district heating. Energy 2016, 110, 1-4, doi:10.1016/j.energy.2016.07.105.

32. Lund, H.; Østergaard, P.A.; Chang, M.; Werner, S.; Svendsen, S.; Sorknæs, P.; Thorsen, J.E.; Hvelplund, F.; Mortensen, B.O.G.; Mathiesen, B.V.; et al. The status of 4th generation district heating: Research and results. Energy 2018, 164, 147159, doi:10.1016/j.energy.2018.08.206. 
33. Connolly, D.; Lund, H.; Mathiesen, B. V; Werner, S.; Möller, B.; Persson, U.; Boermans, T.; Trier, D.; Østergaard, P.A.; Nielsen, S. Heat Roadmap Europe: Combining district heating with heat savings to decarbonise the EU energy system. 2013, doi:10.1016/j.enpol.2013.10.035.

34. Thellufsen, J.Z.; Nielsen, S.; Lund, H. Implementing cleaner heating solutions towards a future low-carbon scenario in Ireland. J. Clean. Prod. 2019, 214, $377-$ 388, doi:10.1016/j.jclepro.2018.12.303.

35. Wiechers, E.; Persson, U.; Grundahl, L.; Connolly, D. Heat Roadmap Europe: Identifying local heat demand and supply areas with a European thermal atlas. 2018, doi:10.1016/j.energy.2018.06.025.

36. Hansen, K.; Connolly, D.; Lund, H.; Drysdale, D.; Thellufsen, J.Z. Heat Roadmap Europe: Identifying the balance between saving heat and supplying heat. Energy 2016, 115, 1663-1671, doi:10.1016/j.energy.2016.06.033.

37. Mohammadi, A.; Mehrpooya, M. A comprehensive review on coupling different types of electrolyzer to renewable energy sources. Energy 2018, 158, 632-655, doi:10.1016/j.energy.2018.06.073.

38. De Santoli, L.; Lo Basso, G.; Bruschi, D. A small scale H2NG production plant in Italy: Techno-economic feasibility analysis and costs associated with carbon avoidance. Int. J. Hydrogen Energy 2014, 39, 6497-6517, doi:10.1016/j.ijhydene.2014.02.003.

39. Varone, A.; Ferrari, M. Power to liquid and power to gas: An option for the German Energiewende. 2015, doi:10.1016/j.rser.2015.01.049.

40. Qadrdan, M.; Abeysekera, M.; Chaudry, M.; Wu, J.; Jenkins, N. Role of power-togas in an integrated gas and electricity system in Great Britain. Int. J. Hydrogen Energy 2015, 40, 5763-5775, doi:10.1016/j.ijhydene.2015.03.004.

41. Nastasi, B.; Lo Basso, G. Power-to-Gas integration in the Transition towards Future Urban Energy Systems. Int. J. Hydrogen Energy 2017, 42, 23933-23951, doi:10.1016/j.ijhydene.2017.07.149.

42. Jia, Q.S. On supply demand coordination in vehicle-to-grid - A brief literature review. In Proceedings of the Proceedings - 2018 33rd Youth Academic Annual Conference of Chinese Association of Automation, YAC 2018; Institute of Electrical and Electronics Engineers Inc., 2018; pp. 1083-1088.

43. Kempton, W.; Tomić, J. Vehicle-to-grid power implementation: From stabilizing the grid to supporting large-scale renewable energy. J. Power Sources 2005, 144, 280-294, doi:10.1016/j.jpowsour.2004.12.022. 
44. Esther, S.; Singh, S.K.; Goswami, A.K.; Sinha, N. Recent Challenges in Vehicle to Grid Integrated Renewable Energy System: A Review. In Proceedings of the Proceedings of the 2nd International Conference on Intelligent Computing and Control Systems, ICICCS 2018; Institute of Electrical and Electronics Engineers Inc., 2019; pp. 427-435.

45. Lisovich, M.A.; Mulligan, D.K.; Wicker, S.B. Inferring personal information from demand-response systems. IEEE Secur. Priv. 2010, 8, 11-20, doi:10.1109/MSP.2010.40.

46. Mancini, F.; Romano, S.; Basso, G. Lo; Cimaglia, J.; Santoli, L. de How the Italian Residential Sector Could Contribute to Load Flexibility in Demand Response Activities: A Methodology for Residential Clustering and Developing a Flexibility Strategy. Energies 2020, 13, 3359, doi:10.3390/en13133359.

47. Mancini, F.; Nastasi, B. Energy retrofitting effects on the energy flexibility of dwellings. Energies 2019, 12, doi:10.3390/en12142788.

48. Mancini, F.; Basso, G. Lo; De Santoli, L. Energy use in residential buildings: Characterisation for identifying flexible loads by means of a questionnaire survey. Energies 2019, 12, doi:10.3390/en12112055.

49. Kim, J.H.; Shcherbakova, A. Common failures of demand response. Energy 2011, 36, 873-880, doi:10.1016/j.energy.2010.12.027.

50. Strbac, G. Demand side management: Benefits and challenges. Energy Policy 2008, 36, 4419-4426, doi:10.1016/j.enpol.2008.09.030.

51. Mancini, F.; Basso, G. Lo; Santoli, L. de Energy use in residential buildings: Impact of building automation control systems on energy performance and flexibility. Energies 2019, 12, 1-17, doi:10.3390/en12152896. 